\title{
A Paradigm Shift in the Planning Profession
}

\author{
Doreen Liberto-Blank \\ $A I C P$; lecturer, CRP Department. \\ Frank Hanna, Lana Russell-Hurd, Tyler English, Laura Lynch, and Ryan Taslim \\ Seniors, BCRP; CRP Department.
}

The planning profession has experienced several paradigm shifts throughout history. Lecturer Doreen LibertoBlank and her students adapted work produced in CRP 436 (Collaborative Planning) for FOCUS. They discuss the profound impact of the Internet, recent technologies, and personal hand-held devices in public outreach.

E vents that irreversibly change history and touch all aspects of society and future generations are an inevitable part of the course of industries and professions. When Johannes Gutenberg created the printing press in 1436 , he revolutionized the production of books. The wide distribution of information made it easier for humans to organize and communicate ideas. In 1517, Martin Luther posted his 95 Thesis that criticized the Catholic Church on the door of Castle Church in Germany, and by taking advantage of the printing press, he was able to distribute it throughout Europe, and ignite the Protestant Reformation.

J.C.R. Licklider, an American computer scientist and academic from MIT, wrote about the "Galactic Network" in 1962 (Leiner et al., 1999). The Internet has evolved since that time and in 1989 the World Wide Web was born (Chapman, 2009). From 1989, the World Wide Web expanded exponentially, reaching commercial markets in 1995. Before this year, the U.S. government primarily funded the Internet. In 2005, there were 198 million Internet users in the United States and more than one billion

Figure 1: Commonly known web tools.

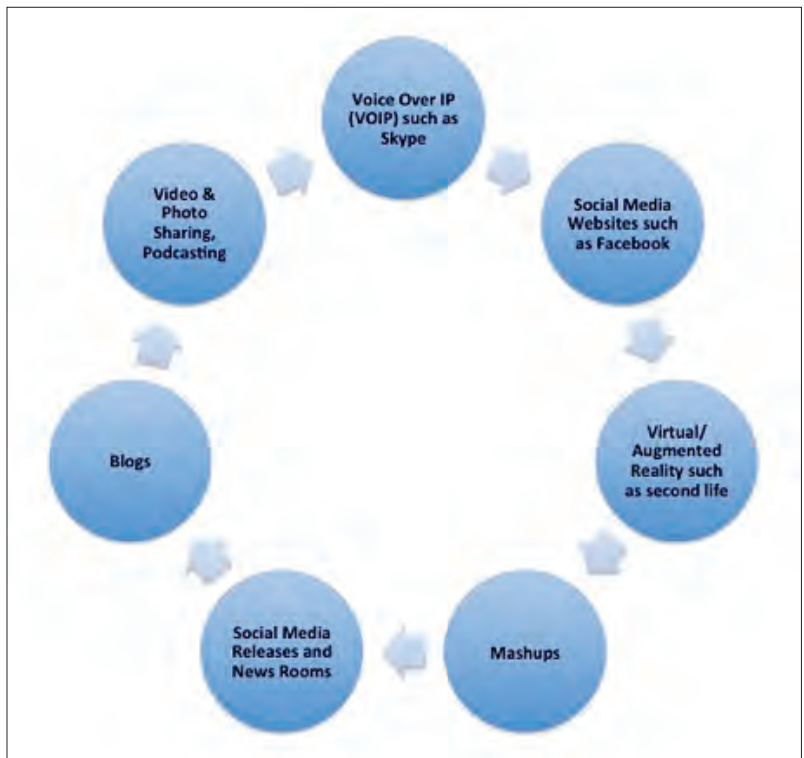

Internet users worldwide. Within five years, usage increased from 254 million to over two billion, respectively. By 2015, it is projected that the United States will have 288 million Internet users and there will be close to 3 billion Internet users worldwide (eTForecasts, n.d.). Today's college student has never known a world without the Internet. The Internet is used to read books, research legal cases, collaborate on development proposals, connect with people from remote corners of the earth, and conduct business around the world. The Internet has changed our personal and business lives forever.

One only has to pick up a newspaper or surf news websites to understand the profound impact the Internet is having on society. The Egyptian revolution started online and drew followers from around the world. The Occupy Wall Street Movement was also organized through the use of social media tools. The computer and Internet have created a global audience for news and events.

\section{The Internet: A Powerful Tool for Planners}

The Internet and the development of certain technologies has become a springboard for supporting the public process and encouraging civic engagement. The value and impact of these tools may lie in the capacity of planners' to utilize them to their fullest extent.

The planning process is steeped in the political process because planners in a democratic society attempt to balance the interest of many different constituencies. In order to understand the need for public participation through new technologies, it is important to look at planning's history of civic engagement. The planning field was previously dominated by rational theories and technical experts, who were proponents of limited civic engagement. Starting in the 1960s planners began to see themselves as facilitators of the citizen view, playing more of a supportive role (Manadarano et al., 2010). This led to dramatic changes in planning practices making public 
participation a routine part of the process. During the 1960s, Paul Davidoff, an attorney and city planner, supported the position that planners must be advocates for those individuals and groups that did not have meaningful access to help shape city plans. Davidoff realized that individuals and groups with money could gain access to the planning process through personal contacts by means that were unavailable to the powerless (Davidoff, 1965). Advocacy planners sponsored community meetings and outreach. The public demanded government at all levels to allow public participation before decisions were made on planning projects. Charettes, community workshops, citizen surveys, and other tools were attempts to gain stakeholder input on planning projects

\section{Public Outreach and Education}

Public outreach and education is vital to the planning process because planning affects the physical development and character of the community. If stakeholders feel that they have been excluded from the planning process, conflicts may arise due to feelings of anger and mistrust of government agencies, which can escalate to costly litigation. The public has increasingly become angrier with government and businesses because they feel information has been misrepresented, and an overwhelming sense of powerlessness to elected leaders (Susskind \& Field, 1996). While public outreach programs are part of a planning process, in many cases participation programs are perfunctory with few, if any, requested changes made.

Traditional methods of engagements such as notices and public meetings have been critiqued for their inability to reach a wide range of individuals and groups in the community. In order to prevent and resolve these conflicts, planners need to do much more. Planners must engage, listen and collaborate with all segments of the community. To do this, it is critical to identify the demographics of a community and determine how best to reach each group of stakeholders. New methods of outreach are being created and implemented through the use of new technologies such as smartphones, computer applications and virtual reality. The traditional form of public outreach such as mailing and newspaper notifications, design charrettes and public workshops, and meetings and hearings reach only a small segment of the community and typically receive little community involvement. In some cases, these approaches may be obstacles to engaging certain segments of society. For example, many times meetings and hearings are conducted at times when lower income households cannot participate due to work and child care concerns. Additionally, individual who are physically disabled or lower income may not have access to transportation to attend meetings. The Latino population is the fastest growing demographic in the United States, yet many communities with growing Latino populations do not conduct meetings or publish documents in Spanish.

Public hearings are still the most common type of public input forums. The formal outreach process can be intimidating, technical, tedious, leaving the most vocal critics or individuals who have vested interests the only ones attending the hearing. Therefore, public participation must shift into the digital age. With emerging advances in communication and information technology that costs little to implement, there is no reason planners should not be using new tools to engage all stakeholders (Castells, 1996).

\section{A Paradigm Shift in Public Outreach Programs}

New technologies can help facilitate the production and distribution of information and are being increasingly used by government agencies to educate and communicate with their citizens (Manadarno et al., 2010). Researchers have found that social media tools help build social capital between government agencies and citizens by sharing information and dialoguing, which can lead to mutual understanding, trust and conflict resolution, as well as more effective and efficient coordination and decision making. Studies have shown that cities with successful public outreach programs include a variety of new technologies such as websites, online forums, visualization and participatory technologies (Kaylor, 2005).

As a final project for the Collaborative Planning class taught at California Polytechnic State University, San Luis Obispo, teams of students were asked to select real world planning projects and prepare a public outreach program using new technology. The use of Facebook and Twitter was discouraged because of its overuse. The purpose for the exercise was to help students become familiar with new technology and be creative in how to use it in the planning profession. The students were encouraged to use the numerous web tools and new technology available to engage segments of communities that normally do not participate in the planning process, improve collaboration with all stakeholders, and build consensus to formulate win-win solutions. The goal of this exercise was to help educate the public about projects and the land use process, and make it easier for the community to provide input on projects. The following case study shares the proposed public outreach program used by one student team based on a project located in the City of San Luis Obispo.

\section{Public Outreach Ideas for Garden Street Terraces, City of San Luis Obispo}

With a population of about 45,000 people, San Luis Obispo is described as one of the happiest places to live. The weather is pleasant year-round, the city is surrounded by hills, there is a walkable historic downtown with a variety of entertainment, and there are plenty of outdoor activities. Mission San Luis Obispo De Tolosa is located along the San Luis Obispo Creek walkway and the central point of Mission Plaza. San Luis Obispo wine country and the Pacific Ocean are nearby, and there is a bounty of world-class restaurants.

The City is known for its progressive public policy and land use approaches. San Luis Obispo was the first community in the country to disallow indoor smoking in public places. Early in 
the City's incorporated history, it also prohibited drive-thru restaurants. City officials were not shy about forward thinking, and did not fear what others might think.

The Garden Street Terraces project is a mixed-use development planned for the downtown (City of San Luis Obispo. 2009). The project is bordered by Garden, Broad and Marsh Streets and includes a variety of uses such as a 48 room hotel with a restaurant, bar and lounge, 11,820 square feet of commercial retail space, 13,227 square feet neighborhood market and eight residential units. It is a unique development due to the pedestrian oriented nature of its design. There are only 40 designated parking spaces located within this project location. Twenty-four of these spaces will be used for the hotel while the other 16 are for the residences of the Garden Street Terraces development.

A variety of goals were established by the Garden Street San Luis Obispo Partners. These include:

- Support downtown as the civic, cultural and social center of the City.

- Contribute to the economic health of Downtown.

- Accommodate the needs of the neighborhood and residents while appealing to visitors.

- Create an exciting, compact and visually interesting mix of uses within a landmark structure based on City policies.

- The City included the following outreach programs as part of the project:

Project Updates to Stakeholder Group: Save Our Downtown (SOD) is a citizens' group formed to protect the character of San Luis Obispo's Downtown core. The participants attended city council and advisory body meetings, and community events and workshops to voice their issues regarding the project. City staff and the applicant provided several standard style presentations throughout the project review process.

City Sponsored Public Hearings/Workshops/Meetings: The City conducted over ten public workshops, meetings and hearings before the cultural heritage committee, architectural review commission, planning commission and city council.

Applicant Sponsored Presentations: The applicant conducted numerous discussions with downtown interests and business owners in the vicinity, including hosting breakfasts.

Physical Model and Computer Simulation: A physical model was prepared in addition to the paper and computer visual renderings. This information was made in direct response to testimony from SOD members for a visual representation of the project for older citizens or others not adept at reading plans or using computers

The lack of public participation from a broad section of the community created a number of issues for the proponents of the project. The project underwent several redesigns, which caused delay and cost the applicant and City time and money. The project was scaled back due to citizen complaints at public hearings. Heights were reduced from 75 feet to 50 feet. The community and local planners continued to contemplate the new design and its proper representation of the character of the City. Without using more tools to reach out to all segments of the City's citizens, it was difficult to determine preferences.

\section{Designing an Alternative Outreach Program}

Based on developing technology and innovation, additional tools are available that the City could have used to enhance the Garden Street Terraces project outreach program. The following outreach tools are examined for their value to the planning field and suggested as additional methods of outreach and public education, specific to the Garden Street Terraces project: Quick Response Codes, Augmented Reality, Online Forums, CommunityViz and CityOne.

\section{Quick Response Code (QR Code)}

A unique way to involve and reach out to the community for the project is to incorporate the use of a technology that involves very little cost to government or the applicant. QR Code or Quick Response Code, seen in Figure 2, allow smartphone users to instantly gain access to information by using their phone's camera and the Internet (Fernando, 2010). QR Codes can be generated without any cost from several websites.

A QR Code is similar to a bar code. It is a box embedded with information that is linked to content on a server. The content can be any digital file, such as a PDF, podcast, video or photo album. QR Codes can be scaled to any size, and printed on any medium or surface; printed small enough to fit on product labels are large enough to fit on a billboard. Tight budgets limit what municipalities and larger governments can do with community outreach and, in theory, QR Code technology could help reach a larger audience with minimal expense.

QR Codes are a way to connect printed content with online content. In that sense, an outreach process would be able to use this technique to make information on the Garden Street Terraces project available at the moment of need. For instance, a QR Code can be posted to provide a map when it is important to give visitors directions without making photocopies. Infor-

Figure 2: GST generated QR code.

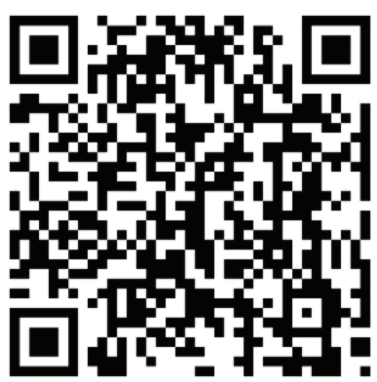


mation is made available at the moment of need rather than hours or weeks after.

QR Codes can be easily applied as a powerful community engagement tool because QR Codes bridge the gap between project websites and users. People have knowledge, resources, information, tools, and experiences from online that we can and should exploit offline (Wisniewski, 2010).

An outreach process that involves posting a $\mathrm{QR}$ code at an on-site kiosk, as seen in Figure 3, or spreading these codes throughout a target, are great examples of ways to reach the stakeholders in the area who are most effected. Website visits are trackable through free websites such as BeeTagg, where it is possible to see how often codes are being read or even generate demographic information from those who visit the area by linking the QR Code to a quick survey. The application of this idea is simple and cost effective, which could establish this outreach strategy as extremely valuable in further engaging the community in the Garden Street Terraces project.

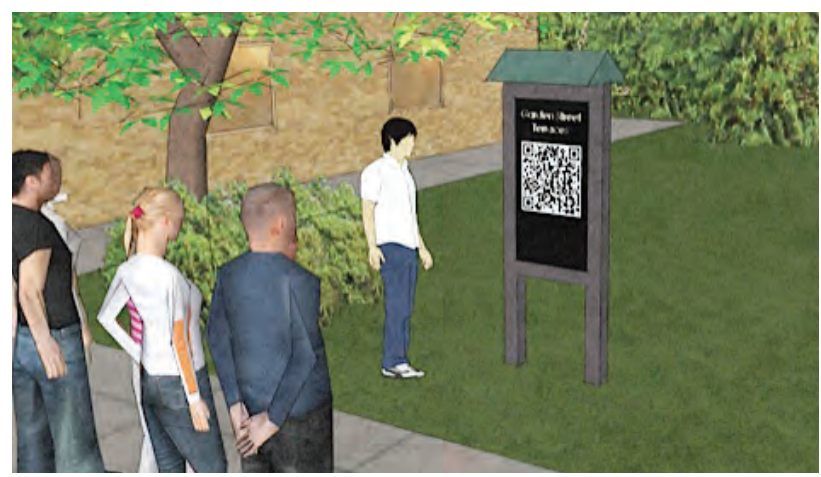

Figure 3: A kiosk with a QR code.

\section{Virtual/Augmented Reality}

As people lose interest in public meetings and hearings and become familiar with technology and virtual reality, the planning profession will need to adapt. While traditional community meetings should not be omitted from public outreach programs, it is imperative plannersn find ways to engage stakeholders. This requires modifying meetings to current interests and interaction with a greater percentage of the population.

Virtual reality is being used to engage people in dialogue in a way not previously possible. Eric Gordon, Assistant Professor in the Department of Visual and Media Arts at Emerson College, used Second Life, an online 3-D virtual world to involve residents of Boston in developing a Master Plan for Chinatown. In a typical workshop or hearing, two-dimensional plans are presented on a project. While planners and architects may understand what is being shown, the typical community member may not have the technical expertise to read the plan. By using virtual technology, residents are able to see projects in threedimensions. Eric Gordon led the Participatory Chinatown Project, which enabled the public to use 3-D gaming technolo- gies to help in the community design process. Through the use of avatars, participants were asked to make choices about a neighborhood. These virtual experiences and comments helped shape real life decisions about their community.

Augmented Reality (AR) is a recent development defined as applications that involve the overlay of virtual imagery on the real world (AR Toolkit). AR is commonly found in many different fields including: television, sports broadcasting, and video games. One commonly known example of AR is found when watching American Football. When the yellow yard line is displayed on the screen, this appears to be on the actual field, but in actuality it is just a digital icon on the screen.

AR has recently evolved to be used within various smartphone applications. Some AR applications will even have an impact on planning and development in general. One smartphone application by NAi, a company from the Netherlands, enables smartphone user to see what a project development has looked like in the past and what it will look like in the future. This application allows the public to understand what a project will look like as a result of computer-generated models being displayed in the place of development.

A company in the United States known as Argon has also developed an application that employs AR technology. While Argon technology only shows the future of the project and focuses on the construction phase, this application is still a valuable resource. Argon's application has most recently been used at Georgia Tech to conceptualize a new campus building.

Here's how AR technology works: when an smartphone user stands on a designated location within the surrounding area, they hold their smartphone up to the construction area and see what the building will eventually look like. The iPhone user can see the digital rendering of the proposed building and can receive additional information about the site and construction by clicking on links to the development's website (Figure 4). Additional information shared includes details about building materials and height. There is also an option for the architect to upload video describing the project in detail.

These examples of virtual reality and AR applications allow for better communication and understanding between community, developer and planners. This allows for developers and community to easily express their likes and dislikes about a project. These technologies also involve members of the public that would usually not go to workshops and planning commission meetings such as young adults, however, AR applications are exclusive to those members of the community that have iPhones. Planners are able to build a better relationship with the community and the developer to ensure that both sides fully understand the proposed project and the desires on each side are met. These technologies allow for the developer to work and collaborate with the community to gain support and create a final project that satisfies the greater public. 


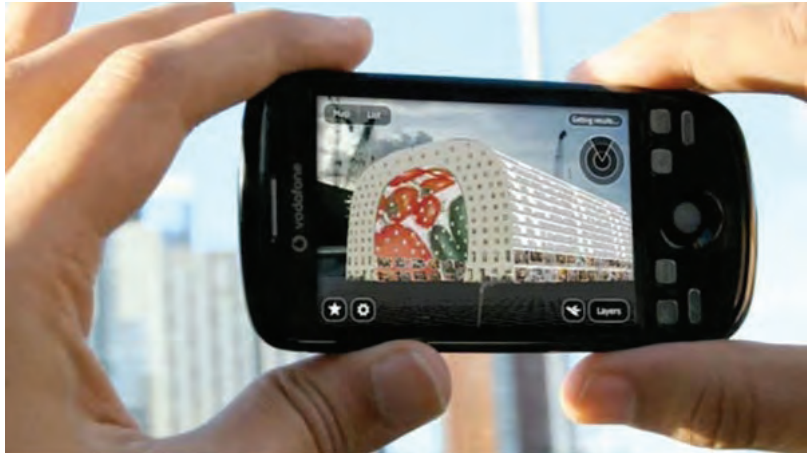

Figure 4: AR apps show current and future development.

The Garden Street Terraces project could have gained more support from the community with the use of these or similar technologies. The community could have understood the size of the proposed buildings and had a greater understanding of scale and feel. This powerful communication tool has the ability to strengthen the rapport between developer and community.

\section{$\underline{\text { Online Forums }}$}

Online discussion forums are a free tool that planners can use to educate and allow citizens to provide feedback on projects and plans. They are online sites where people can hold conversations in the form of posted messages, have been widely used by European governments, and have been gaining popularity in the US (Saebo et al., 2010). Online forums can be linked to QR Codes and provide a vibrant online space where citizens, elected officials, government employees, and community leaders with diverse ideas and from diverse backgrounds can discuss the importance of local issues (E-Democracy.Org, 2008). This allows for an open dialogue to occur between different community members to ask questions and discuss their concerns.

The developers of Garden Street Terraces or the City's Planning staff could have created an online discussion forum for the project in order to allow citizens who were concerned about the scale of the project to shared their views and obtain a response. Additionally, the majority of citizens involved in the Garden Street Terraces project were middle-aged or elderly. An online forum would have helped get harder to reach groups, such as young adults, to participate in the planning process (Smith, 2008). Online forums are a cheap and easy way to get more citizens informed and involved with projects and plans and should be implemented for future projects.

\section{CommunityViz}

CommunityViz is an ArcGIS based decision-support system and is one of today's leading off-the-shelf software programs for integrated, real-time interactive modeling and visualization of planning scenarios. According to an article by Jonathan D. Salter, CommunityViz is structured to analyze indicators and scenarios against multiple management objectives or perfor- mance criteria. Criteria can be customized according to relevant issues at hand (Salter, 2009). CommunityViz is a three-way spatial communication tool. It is used for scenario planning in which future projections can be calculated for developments. CommunityViz is used as a way to create GIS simulations based on the ArcGIS platform that allow decision makers as well as planners and citizens to peer into a projection of the future. Figure 5 shows what CommunityViz applications can look like. The program's projections are not a 100\% accurate, however, CommunityViz presents a "what if" situation to users and viewers depending on the designer's data inputs.

CommunityViz could have been used during public meetings for the Garden Street Terraces project as a three-way communication program, which would have allowed citizens, developers and elected officials to create alternative designs and to better understand the environmental and economic impacts of their proposed alternatives.By understanding this information all stakeholders in the planning process can be more knowledgeable about the benefits and costs of the proposed scenarios, and elected officials could make more informed decisions about which alternatives should be chosen.

\section{CityOne}

This computer application developed by IBM is a video game that puts users into the role of being a city planner, trying to solve the sorts of business and environmental problems that grip today's modern cities. The ultimate aim for this game is to teach the public how to better cope with complex modern problems by showing them the variety of solutions that have to be evaluated, ranging from technologu such as smart grids, to better IT, to smart environmental policy (Kuang, 2010). As it relates to Garden Street Terraces, this application allows users the opportunity to understand the interconnectedness of the many decisions that planners have to make. The game was created to help urban planners, civic and business leaders make cities "smarter" or more environmentally and socially sustainable.

\section{Figure 5: CommunityViz application.}

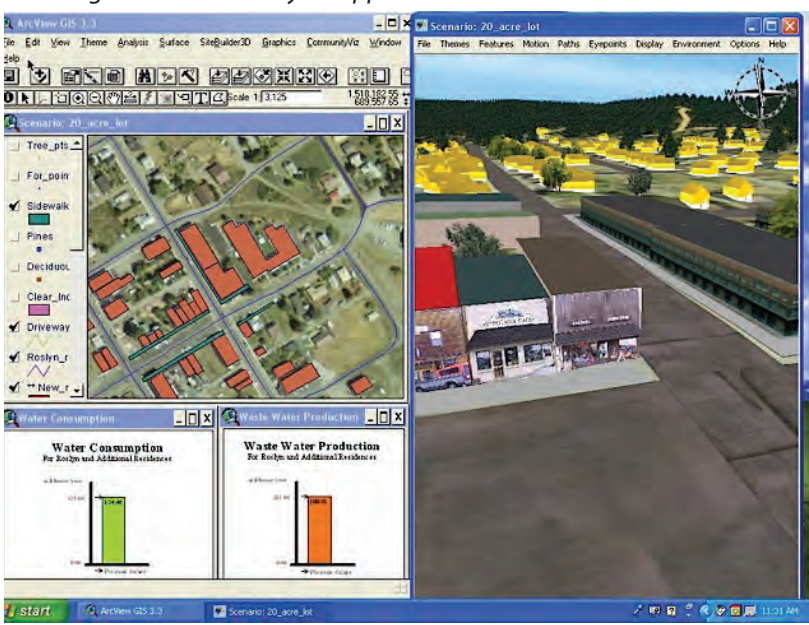


The game's premise is based on real world statistics: Cities already consume $75 \%$ of the world's energy and cause $80 \%$ of its carbon emissions. The world's urban population is expected to double by 2050 and is growing at a blistering pace. Cities have to grow smarter if they plan to support the massive population migrations that are happening worldwide (Kolodny, 2010). CityOne is often compared to another game called Sim City, however, differs because the inputs include true energy, water, banking, and retail information that planners and nonplanners-alike would be faced with. (See Figure 7)

In theory, the game could be tailored to addressing the planning issues faced by the planners of the Garden Street Terraces Project and would help the public understand the intricacies of urban planning.

\section{Conclusion}

New social media technologies are increasingly being utilized by government to enhance public outreach. Planners and developers can use these tools to better inform, educate and receive feedback from citizens about plans and projects. Less traditional and newer technologies have the potential to reach more citizens, especially underrepresented groups, such young adults, as well as provide the opportunity for developers, government officials and citizens to dialogue, to become more knowledgeable, and collaborate to create a projects that meet the interests of all shareholders in the planning process.

The communication and technology field is constantly evolving, and the possibilities are only constrained by the innovative thinking of the planner. The application of technology is growing exponentially and can be intimidating, especially to seasoned planning professionals. Planners should feel comfortable to explore the ways applications can lead to better public participation, dialogue, collaboration, and learning. Technology provides planners with supplemental tools to design communities that reflect the needs of those individuals not involved in the traditional outreach process. Since the field is rapidly emerging and changing one thing is clear, professional planners need to be flexible enough to try new and innovative means to gain valued input, and evolve with changing trends in technology.

\section{References}

Castells, M. 1996. The Rise of the Network Society. Cambridge, MA: Blackwell.

Chapman, C. 2009. The History of the Internet in a Nutshell. Retrieved from sixrevisions.com/resources/the-history-of-theinternet-in-a-nutshell/.

City of San Luis Obispo. 2009. Environmental Impact Report of the Garden Street Terrace Project. Retrieved from http:// gardenstreetterraces.com/pdfs/Garden Street Final EIRVolume_I.pdf.

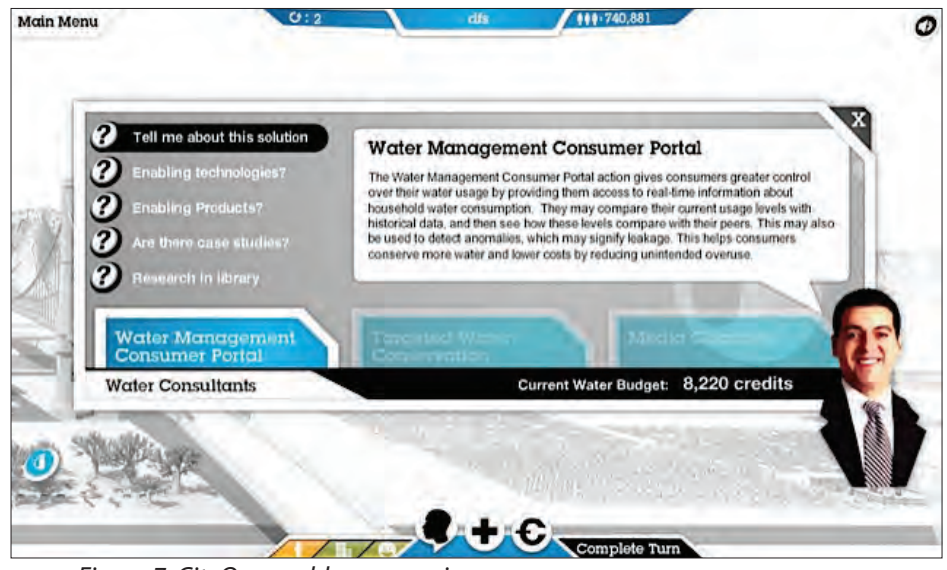

Figure 7: CityOne problem scenario.

Davidoff, P. 1965. Advocacy and Pluralism in Planning. Journal of the American Institute of Planners 31 (4), 331-338.

E-Democracy.Org. 2008. Minneapolis Issues Forum Charter. Retrieved from http://forums.e-democracy.org/groups/mpls/ charter.

eTForecasts (n.d.) Retrieved from http://www.etforecasts.com/ products/ES_intusersv2.htm.

Fernando, A. 2010. Start Taking in Code. Communique, pp 8-9.

JISC Technology and Standards Watch (2007). Retrieved from http://www.jisc.ac.uk/whatwedo/services/techwatch/reports/horizonscanning/hs0701.aspx.

Kaylor, C. 2005. The State of Local E-Government and E-Democracy: Benchmarking the Progress of U.S. Cities at Providing Online Opportunities for Citizen Engagement. Columbus, $\mathrm{OH}$ : Institute for Public Service and Public Policy.

Kolodny, L. 2010. IBM Releases CityOne, A "Serious Game," For Urban Planners, Civic Leaders And Executives. TechCrunch.

Kuang, C. (2010). IBM's CityOne Is Like Sim City, Except the Solutions Are Real. Fast Company.

Leiner, Barry, et al. 1999. A Brief History of the Internet. Retrieved from http://www.isoc.org/internet/history/brief.shtml

Mandarano, L., M. Meenar \& C. Steins. 2010. Building social capital in the digital age of civic engagement. Planning Literature, 25, 123-135.

Saebo, O., Rose, J. \& Molka-Danielsen, J. 2010. Eparticipation: Designing and managing political discussion forums. Social Science Computer Review, 28, 403-426.

Salter, J. D. 2009. The digital workshop: exploring the use of interactive and immersive visualization tools in participatory planning. Journal of Environmental Management, 6, 90-101.

Suskind, L. \& P. Field. 1996. Dealing With An Angry Public.

Wisniewski, J. 2010. Bridging the Other Digital Divide. Online Magazine, pp 55-57. 